\title{
Ozone Chemistry during the 2002 Antarctic Vortex Split
}

\author{
Jens-Uwe Grooß, Paul Konopka, and Rolf Müller \\ Institut für Chemie und Dynamik der Geosphäre: Stratosphäre (ICG I), Forschungszentrum Jülich, Jülich, Germany
}

(Manuscript received 15 May 2003, in final form 16 April 2004)

\begin{abstract}
In September 2002, the Antarctic polar vortex was disturbed, and it split into two parts caused by an unusually early stratospheric major warming. This study discusses the chemical consequences of this event using the Chemical Lagrangian Model of the Stratosphere (CLaMS). The chemical initialization of the simulation is based on Halogen Occultation Experiment (HALOE) measurements. Because of its Lagrangian nature, CLaMS is well suited for simulating the small-scale filaments that evolve during this period. Filaments of vortex origin in the midlatitudes were observed by HALOE several times in October 2002. The results of the simulation agree well with these HALOE observations. The simulation further indicates a very rapid chlorine deactivation that is triggered by the warming associated with the split of the vortex. Correspondingly, the ozone depletion rates in the polar vortex parts rapidly decrease to zero. Outside the polar vortex, where air masses of midlatitude origin were transported to the polar region, the simulation shows high ozone depletion rates at the 700-K level caused mainly by $\mathrm{NO}_{\mathrm{x}}$ chemistry. Owing to the major warming in September 2002, ozone-poor air masses were transported into the midlatitudes and caused a decrease of midlatitude ozone by $5 \%-15 \%$, depending on altitude. Besides this dilution effect, there was no significant additional chemical effect. The net chemical ozone depletion in air masses of vortex origin was low and did not differ significantly from that of midlatitude air, in spite of the different chemical composition of the two types of air masses.
\end{abstract}

\section{Introduction}

During September 2002, a major stratospheric warming occurred that led to the split of the polar vortex into two parts (Newman and Nash 2005). Such an event has never been reported before. One of the vortex parts stabilized itself again, while the other one, which contained a significant part of the vortex mass, was transported into the midlatitudes, where fragments of this part did mix with the surrounding air on time scales well above 1 month (Konopka et al. 2005).

Hoppel et al. (2003) report observations by the Polar Ozone and Aerosol Measurement (POAM) that show that ozone depletion did not continue inside the vortex after the time of the vortex split. Sinnhuber et al. (2003) show that the estimated chemical ozone loss averaged over the polar region between $60^{\circ}$ and $90^{\circ} \mathrm{S}$ (including extravortex air) by the end of October was comparable to earlier winters, although the chemical ozone depletion inside the polar vortex was terminated by the major stratospheric warming much earlier than in normal ozone hole winters.

Corresponding author address: Dr. Jens-Uwe Grooß, Institut für Chemie und Dynamik der Geosphäre: Stratosphäre (ICG I), Forschungszentrum Jülich, 52425 Jülich, Germany.

E-mail: j.-u.grooss@fz-juelich.de
This study focuses on the ozone chemistry of the air masses both inside and outside the polar vortex and uses the Chemical Lagrangian Model of the Stratosphere (CLaMS) to investigate how chemical ozone depletion is affected by this unusual dynamical situation. Inside the vortex, the chlorine deactivation process is also investigated in detail. Furthermore, the unusual advection of former vortex air into the midlatitudes as well as the advection of midlatitude air masses to the polar region and the chemical consequences of this were investigated. To this end, individual ozone depletion cycles and their contribution to the ozone loss were calculated.

\section{Simulation}

\section{a. Model description}

CLaMS is described in detail elsewhere (McKenna et al. 2002a; McKenna et al. 2002b). Unlike most other chemical transport models, it is based on a Lagrangian principle, that is, it uses a grid distributed quasiuniformly but irregularly in space where the grid boxes represent individual air parcels whose movement is simulated instead of using a space-fixed grid. The mixing between the air parcels is simulated inhomogeneously in space where the mixing intensity is controlled by the strength of deformation of the flow 
(McKenna et al. 2002b; Konopka et al. 2003b). The model contains a comprehensive set of photochemical and heterogeneous reactions of stratospheric relevance (McKenna et al. 2002a).

The simulation presented here covers the whole Southern Hemisphere with a horizontal resolution of $100 \mathrm{~km}$ in each model level. It starts on 1 September 2002 and runs until 17 October. Wind and temperature information was taken from European Centre for Medium-Range Weather Forecasts (ECMWF) operational analyses with high spatial and temporal resolution $\left(1.125^{\circ} \times 1.125^{\circ} ; 6 \mathrm{~h}\right)$. The transport characteristics of this model setup were successfully validated using a variety of datasets including satellite data from the Cryogenic Infrared Spectrometers and Telescopes for the Atmosphere (CRISTA) (McKenna et al. 2002b), the Halogen Occultation Experiment (HALOE; Konopka et al. 2003a), and the Microwave Limb Sounder (MLS) and the Improved Limb Atmospheric Sprectrometer (ILAS; McKenna et al. 2002a), as well as from in situ data measured on board the ER-2 aircraft (Grooß et al. 2002; Konopka et al. 2003b) and by ozonesondes (McKenna et al. 2002a).

The simulation was performed on six isentropic surfaces between the potential temperature levels of 425 and $700 \mathrm{~K}$. The vertical motion caused by diabatic heating or cooling of the air masses has been neglected here. This assumption is justified because of the relatively small amount of diabatic descent over the simulation period. To verify that, the diabatic descent was determined by the CLaMS trajectory module using the incorporated radiation scheme (Morcrette 1991). The 3D trajectory calculation for the vortex air masses at the $475-\mathrm{K}$ level indicates an average descent of $20 \pm 7 \mathrm{~K}$ over the 47-day simulation period corresponding to less than $1 \mathrm{~km}$ of altitude. Furthermore, the comparison with data from HALOE (Russell et al. 1993) indicates the relatively small deviations that are introduced by the isentropic approximation (see below).

The possible polar stratospheric cloud (PSC) particles considered here are supercooled ternary solution (STSs), sulfuric acid tetrahydrate (SAT), nitric acid trihydrate (NAT), and water ice (McKenna et al. 2002a). A parameterization of denitrification was used that was derived for the CLaMS simulation in the Arctic winter of 1999/2000 (Grooß et al. 2002). Briefly, the settling velocities of the simulated NAT and ice PSC particles are calculated. From these settling velocities the corresponding downward mass flux of $\mathrm{H}_{2} \mathrm{O}$ and $\mathrm{HNO}_{3}$ is deduced. It is assumed to be proportional to the settling velocity. Renitrification of the air masses below by evaporating PSC particles cannot be considered by this method. Therefore, the study focuses mainly on altitudes above $475 \mathrm{~K}$, where renitrification should be negligible. Because of the uncertainties of this method, sensitivity simulations with respect to the denitrification parameterization were performed as described below.

\section{b. Initialization}

The chemical composition of the air masses at the start of the simulation was derived from observations of HALOE in the Southern Hemisphere between 10 and 30 August 2002 well before the major warming event. During this period, the polar vortex was still unperturbed, and the observed mixing ratios correlated well with potential vorticity (PV). Thus, a correlation between $\mathrm{PV}$ and mixing ratios of $\mathrm{O}_{3}, \mathrm{HCl}, \mathrm{CH}_{4}$, and $\mathrm{H}_{2} \mathrm{O}$ was established. Figure 1 shows an example of these correlations between PV and HALOE observations of ozone and $\mathrm{CH}_{4}$. A spline fit to each of these correlations (red lines in Fig. 1) was used together with analyzed PV to derive a hemispheric distribution of these chemical species on the isentropic levels considered. Total inorganic chlorine $\mathrm{Cl}_{y}$ was derived from $\mathrm{CH}_{4}$ and the $\mathrm{CH}_{4} / \mathrm{Cl}_{y}$ correlation deduced for the Arctic stratosphere in 2000 (Grooß et al. 2002). The remaining species were derived from the Mainz photochemical 2D model (Grooß 1996) that simulates a zonal averaged latitude/altitude domain. These 2D model results were mapped to PV equivalent latitude.

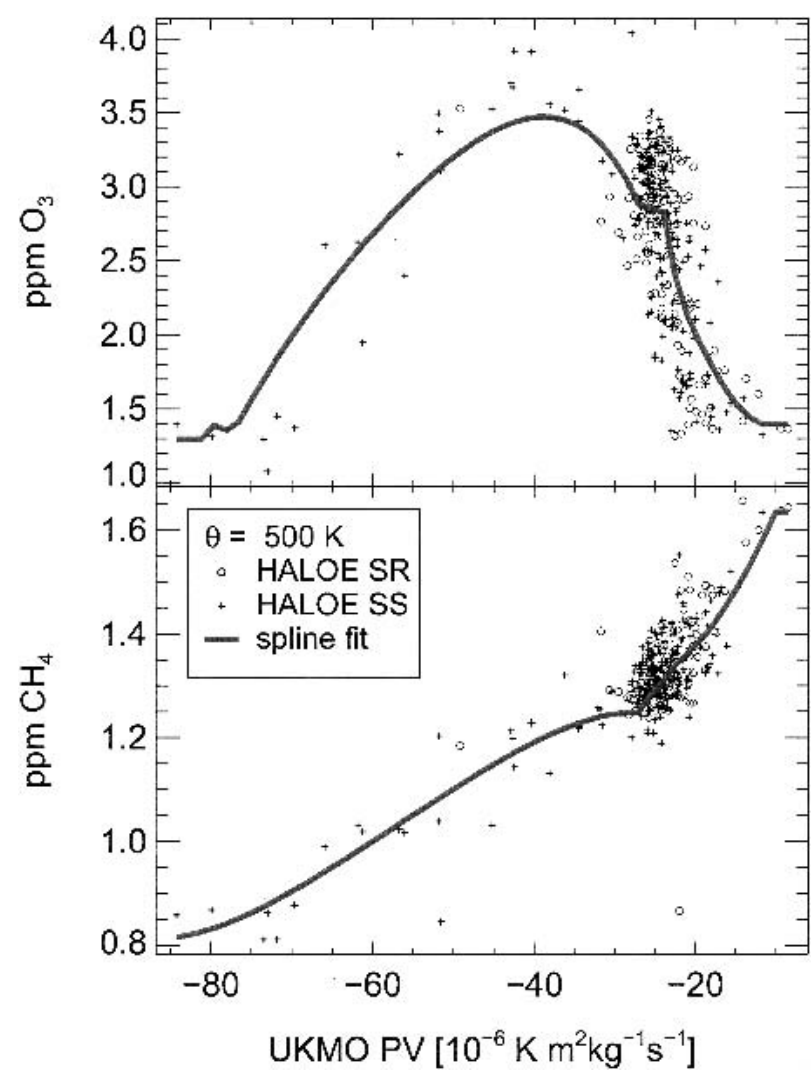

FIG. 1. Example of correlation between PV and HALOE observation of $\mathrm{O}_{3}$ and $\mathrm{CH}_{4}$ on the 500-K level. HALOE sunrise and sunset data between 10 and 30 Aug 2002 are depicted as circles and pluses, respectively. The solid line shows the spline fit that was used to derive the initialization. 


\section{Simulation results}

\section{a. Comparison with HALOE observations}

To validate the model approach employed including the initialization and the assumptions and simplifications made, the simulation results were compared to HALOE observations toward the end of the simulation period in early and mid-October. HALOE has a sparse coverage of typically 15 observations per day in each hemisphere at about constant latitude. Nevertheless, these data are well suited for validating the simulation, because of the highly asymmetric form of the vortex, HALOE sampled air both of midlatitude and vortex origin in October.

Figure 2 shows examples of this comparison. The HALOE observations are overplotted on the CLaMS simulation results as colored circles. The displayed locations of the observations correspond to the synoptic time 1200 UTC on the given date and was determined from the observation time and location by the CLaMS trajectory module. On 3 October on the 600-K level, the air masses of the vortex part that had been transported to the midlatitudes were sampled by HALOE at around $90^{\circ}$ and $115^{\circ} \mathrm{W}$ and are noticeable in all HALOE species. The agreement in the chemically long-lived tracer $\mathrm{CH}_{4}$ indicates that the transport of these air masses is represented reasonably well in the model. The agreement in ozone and $\mathrm{HCl}$ suggests reasonable assumptions for ozone initialization and realistic simulation of the chlorine chemistry and the chemical ozone depletion inside the vortex. Similarly, HALOE observed a filament of air with vortex origin
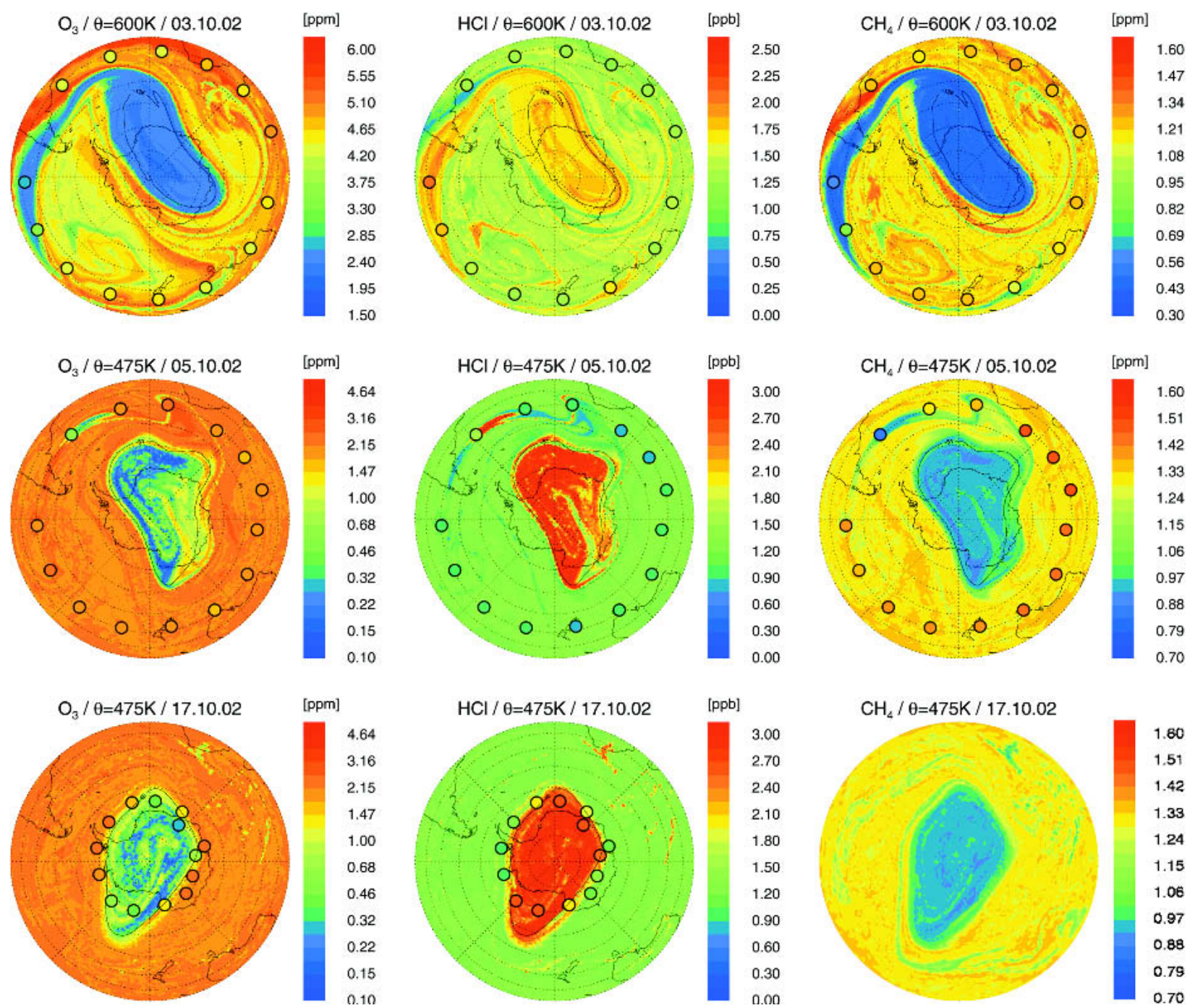

FIG. 2. Results of the CLaMS simulation of (left) ozone, (middle) $\mathrm{HCl}$, and (right) $\mathrm{CH}_{4}$. Shown are the dates after the vortex split event for which HALOE data in the vortex or its remnants are also available: (top) 3 Oct, $\theta=600 \mathrm{~K}$; (middle) 5 and (bottom) 17 Oct, $\theta=475 \mathrm{~K}$. The filled colored circles indicate mixing ratio observed by HALOE at their corresponding synoptic location at $1200 \mathrm{UTC}$. 

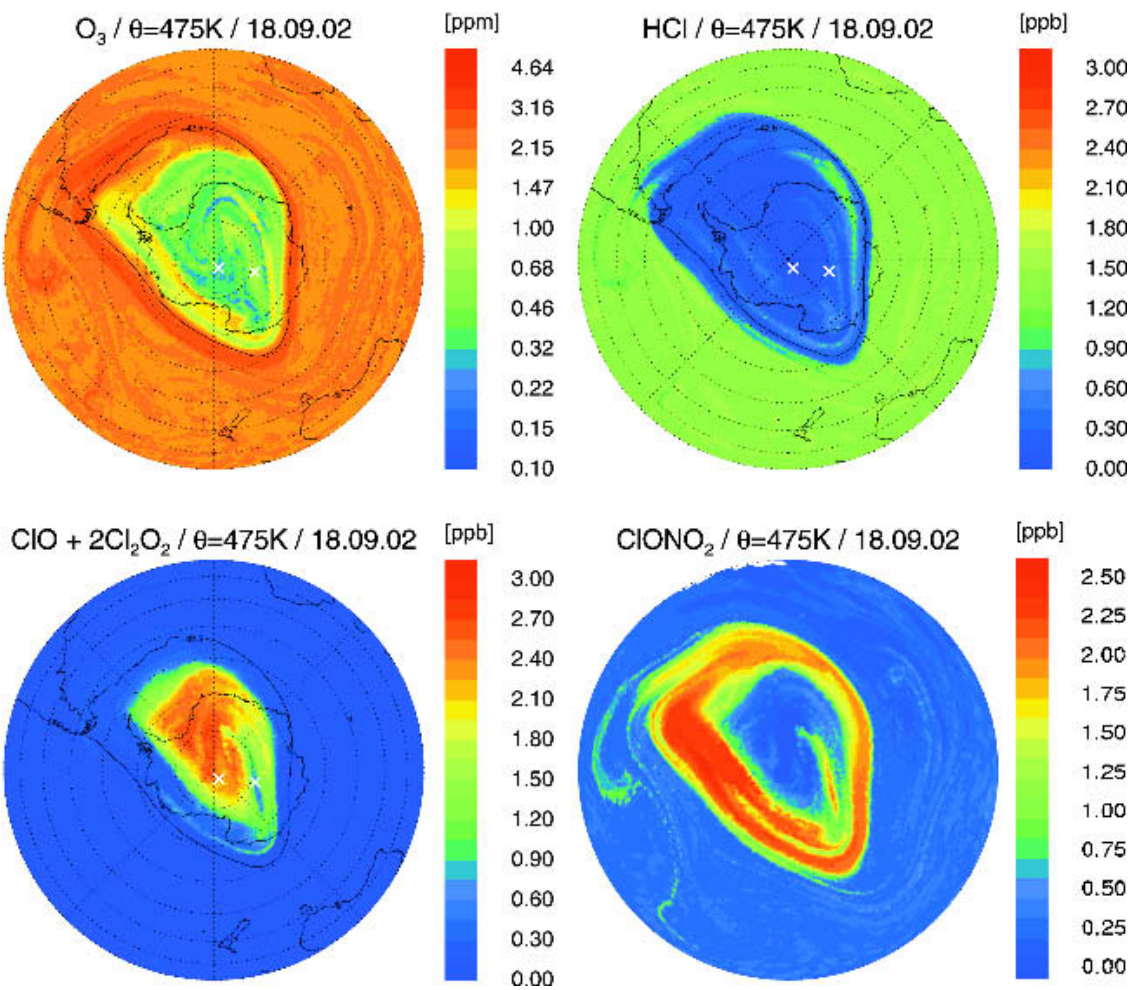

FIG. 3. Results of the CLaMS simulation of ozone, $\mathrm{HCl}, \mathrm{ClONO}_{2}$, and active chlorine $\mathrm{ClO}_{x}$ $\left(=\mathrm{ClO}+2 \mathrm{Cl}_{2} \mathrm{O}_{2}\right)$ for 18 Sep. For the air masses marked with white crosses, the time dependence of chlorine deactivation is plotted in Fig. 5.

at about $45^{\circ} \mathrm{W}$ on 5 October at the $475-\mathrm{K}$ level. Here, there seems to be a slight overestimation of $\mathrm{HCl}$ by the simulation. This is probably caused by the averaging in the observations over the HALOE field of view. On 17 October, the HALOE observations are located around $80^{\circ} \mathrm{S}$ and cover the polar vortex better. Here, remarkable agreement is seen between simulation and observation of ozone and $\mathrm{HCl}$. Even the ozone variability within the polar vortex is in agreement (Fig. 3, bottom left). Note that for the $475-\mathrm{K}$ level, the color bar is spaced logarithmically to highlight the variability for low ozone mixing ratios inside the vortex. The $\mathrm{CH}_{4}$ mixing ratios inside the vortex are overestimated by the simulation. This is most likely caused by the isentropic approximation that neglects diabatic descent. Nevertheless, the basic features of horizontal transport and chemistry seem to be covered well by the simulation.

A more detailed analysis and a validation of tracer advection and mixing using the 3D version of CLaMS with a very similar initialization is presented by Konopka et al. (2005). They showed that above about $600 \mathrm{~K}$, a significant part of the vortex air is transported and mixed into the midlatitudes. In contrast, below 600 $\mathrm{K}$, only a small fraction of the polar vortex air was transported to the midlatitudes as filaments, whereas the major part of the vortex air remained isolated despite the enormous dynamical disturbance.

\section{b. Ozone and chlorine compounds}

Figures 3 and 4 show the simulation results at the 475-K level for 18 and 24 September. Shown are the mixing ratios of ozone, the chlorine reservoir species, $\mathrm{HCl}$ and $\mathrm{ClONO}_{2}$, as well as active chlorine $\mathrm{ClO}_{x}=$ $\mathrm{ClO}+2 \mathrm{Cl}_{2} \mathrm{O}_{2}$. On 18 September, the typical structure of the polar vortex is seen. In the core of the vortex, the major fraction of the chlorine species is present in the form of active chlorine. Toward the vortex edge, the so-called $\mathrm{ClONO}_{2}$ collar is seen (Toon et al. 1989). On 24 September, the ongoing split of the vortex is evident in ozone, $\mathrm{HCl}$, and $\mathrm{ClONO}_{2}$ simulations. By that time in most vortex air masses, the chlorine deactivation is almost completed. Moreover, a complementary structure for chlorine deactivation into $\mathrm{ClONO}_{2}$ and $\mathrm{HCl}$ is depicted. Vortex air masses with high $\mathrm{HCl}$ mixing ratios show low $\mathrm{ClONO}_{2}$ and vice versa. The main reason for this complementary structure is found in the ozone mixing ratio as explained below. Generally, the ozone mixing ratio within the polar vortex is very low at the $475-\mathrm{K}$ level. The air masses with ozone mixing ratios below about $0.25 \mathrm{ppm}$ correspond clearly to air masses with high $\mathrm{HCl}$, while those with around $0.6 \mathrm{ppm}$ correspond to high $\mathrm{ClONO}_{2}$.

For clarity, two examples of these complementary air masses are marked with white crosses on the maps. For 

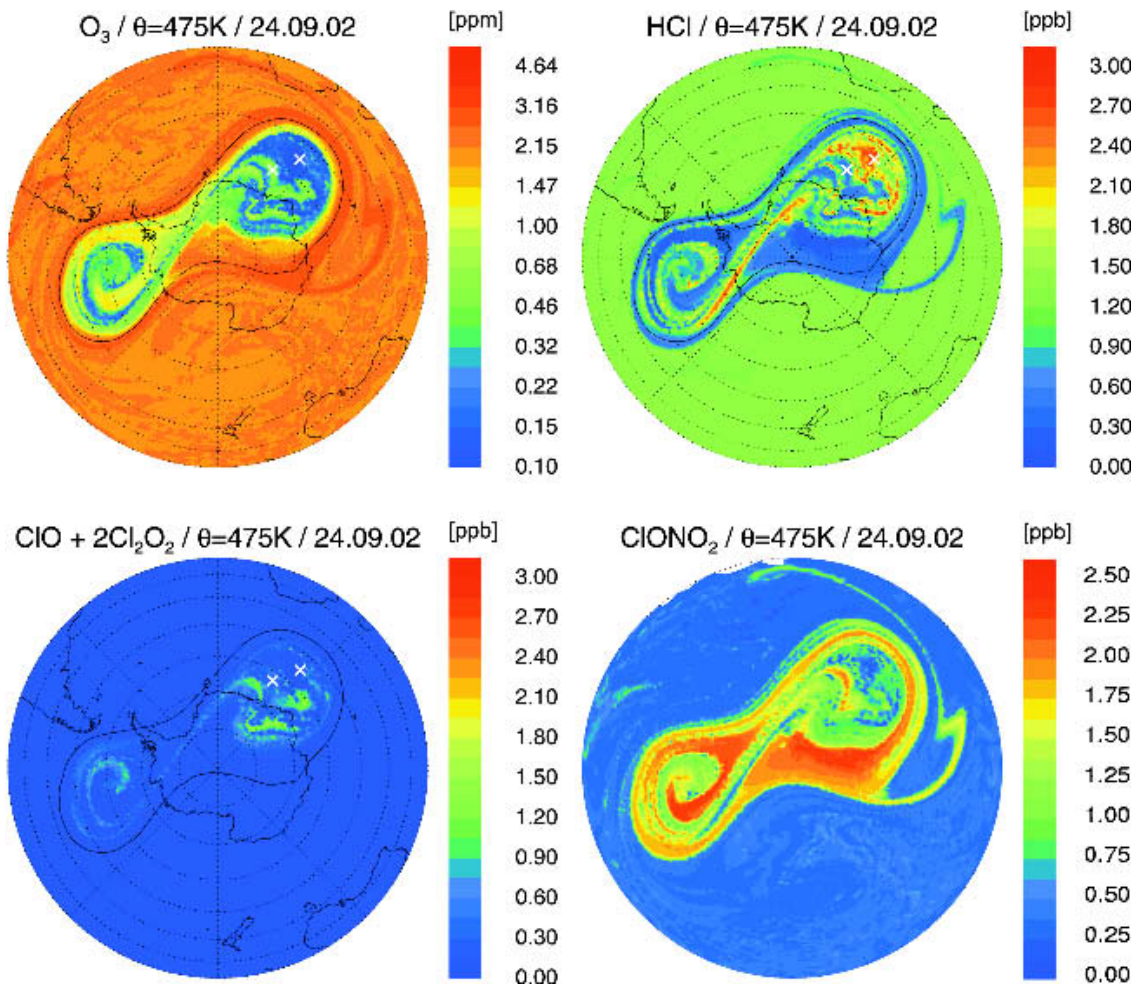

Fig. 4. As in Fig. 3, but for 24 Sep, where the vortex is just about to split into two separate parts. On this day, complementary structure of the chlorine deactivation in the vortex can be seen. Air masses with high $\mathrm{HCl}$ correspond to low $\mathrm{ClONO}_{2}$ and very low $\mathrm{O}_{3}$ mixing ratios.

these air masses, the time series of mixing ratios of chlorine compounds are shown in detail in Fig. 5. The top of Fig. 5 shows the air mass with an ozone mixing ratio of $0.1 \mathrm{ppm}$ on 24 September. The times when PSCs are present are shaded gray. Chlorine deactivation into $\mathrm{HCl}$ is very rapid and starts as soon as PSCs have disappeared. In contrast, Fig. 5 (bottom) shows the other marked air mass that has an ozone mixing ratio of $0.7 \mathrm{ppm}$ on 24 September. Here, the chlorine deactivation is slower and the active chlorine starts to be converted into $\mathrm{ClONO}_{2}$. This is the chlorine deactivation mechanism typically seen in Arctic spring (Douglass et al. 1995).

The main reason for this difference in the chlorine deactivation process is the difference in ozone mixing ratios. Grooß et al. (1997) show that the $\mathrm{HCl}$ formation rate increases with decreasing ozone mixing ratio. In particular, high $\mathrm{HCl}$ formation rates are reported for the very low ozone mixing ratios that are typical of the Antarctic vortex during past decades, which were characterized by a strong stratospheric chlorine burden. The fast $\mathrm{HCl}$ formation is caused by an increase in the $\mathrm{Cl} / \mathrm{ClO}$ ratio for the lower ozone mixing ratios, as the reaction of $\mathrm{Cl}$ radicals with ozone molecules is hindered. This results in a very rapid chlorine deactivation through the reaction of $\mathrm{Cl}+\mathrm{CH}_{4}$. Thus, for the very low ozone mixing ratios of about $0.1 \mathrm{ppm}$, a very fast
$\mathrm{HCl}$ formation rate is simulated in this study. The different ozone mixing ratios of the two air masses are a result of their different histories. The second air mass, characterized by greater ozone mixing ratios $(0.7 \mathrm{ppm}$ on 24 September), originated from the vortex edge region. Here, the simulation suggests less ozone depletion as there was lower chlorine activation. The larger ozone mixing ratio in this air mass causes a lower value of the $\mathrm{Cl} / \mathrm{ClO}$ ratio and thus leads to a slower $\mathrm{HCl}$ formation rate so that the chlorine deactivation proceeds via the formation of $\mathrm{ClONO}_{2}$.

In contrast to the $\mathrm{HCl}$ formation rate, the formation rate of $\mathrm{ClONO}_{2}$ also depends on the availability of $\mathrm{NO}_{2}$. In both air masses considered, very low $\mathrm{NO}_{x}$ mixing ratios below $0.1 \mathrm{ppb}$ were simulated for the time when PSCs were present. However, the air mass that originated from the vortex core was characterized by great denitrification ( $\left.7 \mathrm{ppb} \mathrm{NO}_{y}\right)$ as opposed to the second air mass from the vortex edge region (14 ppb $\mathrm{NO}_{y}$ ). The higher $\mathrm{HNO}_{3}$ mixing ratio in the second air mass constitutes a larger source of $\mathrm{NO}_{x}$ yielding faster chlorine deactivation into $\mathrm{ClONO}_{2}$. As the denitrification in the model is represented by a rather simple parameterization (Grooß et al. 2002), the amount of denitrification may not be simulated completely realistically. However, the $\mathrm{HCl}$ formation rate is almost independent of denitrification, 

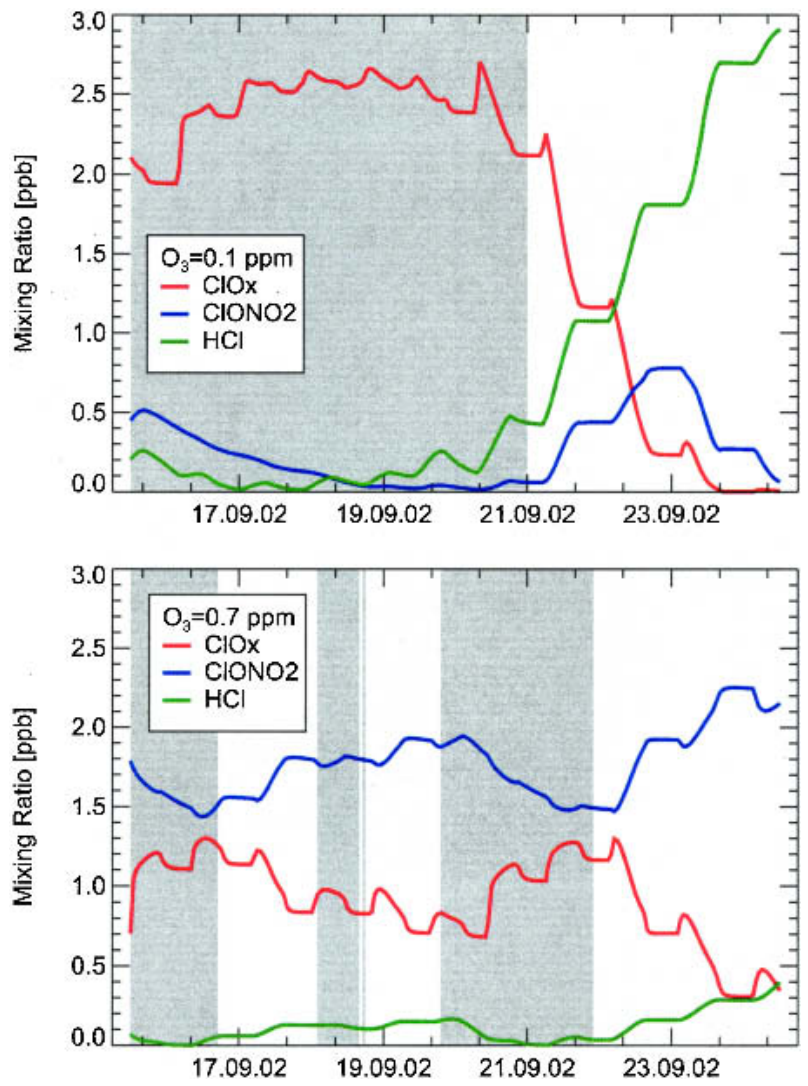

FIG. 5. Time dependence of chlorine species for air parcels at two locations that are marked with white crosses on the maps in Figs. 3 and 4. (top) Air masses with high $\mathrm{HCl}$ and very low ozone mixing ratios $(0.1 \mathrm{ppm})$ on 24 Sep and (bottom) air masses with high $\mathrm{ClONO}_{2}$ and somewhat higher ozone mixing ratios (0.7 ppm). Times where PSCs are present are shaded gray.

which was confirmed by a sensitivity simulation for the second air parcel employing higher denitrification (not shown).

Since the simulated geographic distribution of the chlorine reservoirs depends critically on the ozone mixing ratio, the spatial variability of ozone in the model at the time of initialization is important. As there is not much information about the variability of ozone within the polar vortex in the HALOE data in August, the real geographic distribution of chlorine reservoirs may look somewhat different. Also the simulated denitrification cannot at present be validated by observations. However, the principal feature of a complementary structure of deactivation into the two chlorine reservoirs, $\mathrm{HCl}$ and $\mathrm{ClONO}_{2}$, would be expected to be a robust feature since ozone depletion stopped very quickly because of the unusual temperature rise. This may be proven as further datasets from other sources become available for this period [in particular Environmental Satellite-Michelson Interferometer for Passive Atmospheric Sounding (ENVISAT-MIPAS). Figure 5 also clearly illustrates that the process of chlorine deactiva- tion and the corresponding end of ozone depletion is triggered at the time when temperatures rise above the PSC threshold temperature. A temperature offset in the analyses would only result in a small time shift. For example, between 20 and 27 September, the vortex average temperature rose by $1.7 \mathrm{~K} \mathrm{day}^{-1}$; thus a temperature offset of $1 \mathrm{~K}$ would result in a time delay for chlorine deactivation of about $14 \mathrm{~h}$.

\section{c. Chemical ozone depletion}

For the present simulation, the ozone depletion rates averaged over the polar vortex were determined for the different isentropic levels. The vortex edge definition of Nash et al. (1996) was used to define the vortex area. This definition includes the vortex regions split off the main vortex as long as their potential vorticity remains large enough. The vortex-averaged ozone depletion rates between 425 and $550 \mathrm{~K}$ are depicted as thick colored lines in Fig. 6. Clearly, the ozone depletion rates decrease rapidly after the major warming as a result of
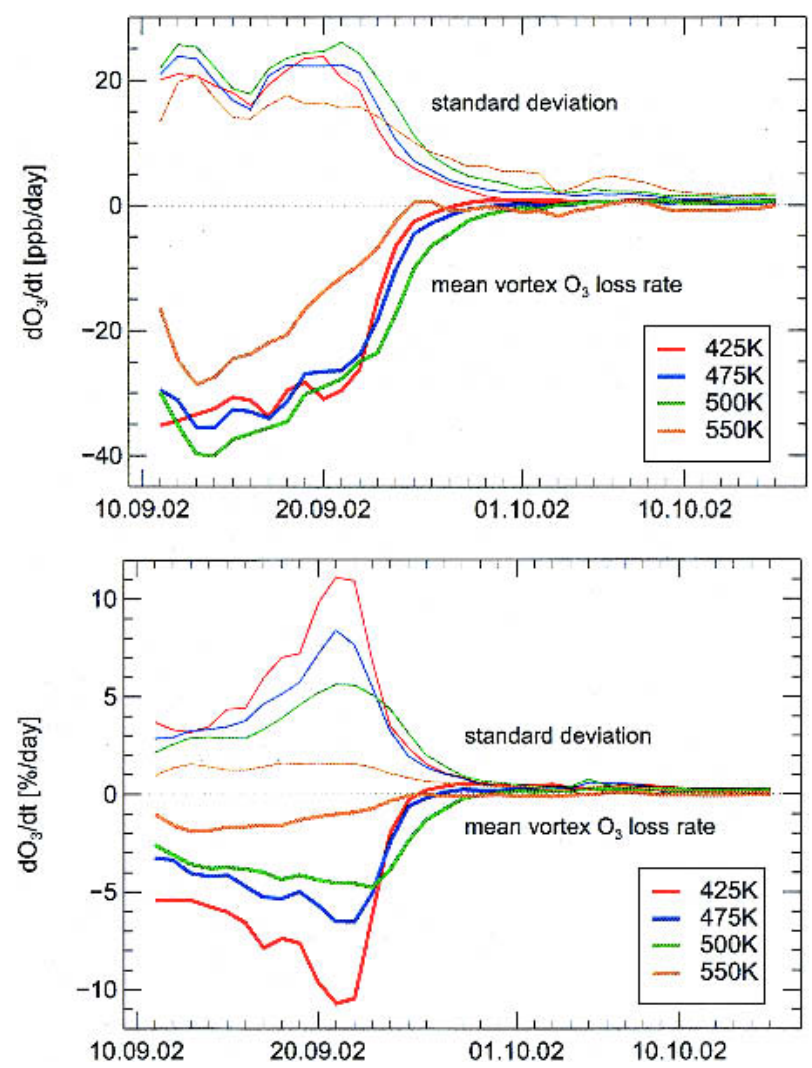

FIG. 6. The simulated ozone depletion rates in (top) $\mathrm{ppb}^{-1}$ and (bottom) $\%$ day $^{-1}$ for different potential temperature levels averaged over the polar vortex as a function of time. The vortex edge was defined according to Nash et al. (1996). The colored thin lines show the corresponding standard deviation. The sudden decrease of ozone loss rates corresponds to the temperature rise inside the vortex at the stratospheric warming event and the resulting chlorine deactivation. 
the fast chlorine deactivation. This is consistent with observations by POAM showing that ozone depletion stopped before it was complete, unlike in earlier years (Hoppel et al. 2003). Similarly, ozonesonde observations at the South Pole station show that after the vortex split, no further ozone depletion occurred (S. Oltmanns 2003, personal communication). Inside the vortex, there is high variability of ozone depletion rates. The corresponding standard deviation $(1 \sigma)$ for the different levels is shown as thin lines in Fig. 6. Before 22 September, a standard deviation of about $20 \mathrm{ppb}$ day $^{-1}$ on all four levels shows that the ozone depletion rate is very inhomogeneous within the vortex. Between 1 and 30 September, the vortex average ozone mixing ratio did decrease by $68 \%, 46 \%, 37 \%$, and $32 \%$ on the $425-$, 475-, 500-, and 550-K potential temperature levels, respectively. With increasing altitude, the chemical ozone depletion in the vortex is lower because of higher temperatures and the resulting lower chlorine activation. On 20 September at the 550-K level, in about two-thirds of the vortex area, toward the vortex edge the chlorine is already deactivated. On 20 September at the $600-\mathrm{K}$ level, the vortex air masses are already completely deactivated.

On the higher levels, the simulation reveals a further consequence of the unusual major warming. Figure 7 shows the simulation results for the $700-\mathrm{K}$ level on 6 October. At that time, the vortex was displaced from the pole. The simulation reproduces ozone and $\mathrm{HCl}$ mixing ratios in the vortex origin filament above $\mathrm{New}$ Zealand. The $\mathrm{CH}_{4}$ mixing ratios in this filament are somewhat overestimated by the simulation as discussed above. Since the vortex is displaced from the pole, midlatitude air masses are transported into the polar region. In these air masses, the simulation indicates high ozone depletion rates of over $100 \mathrm{ppb}$ day $^{-1}$ averaged over 1 day (located over the pole) and even $50 \mathrm{ppb}$ day $^{-1}$ averaged over 1 week. On this level, the ozone mixing ratio of air masses without vortex origin averaged between $50^{\circ}$ and $90^{\circ} \mathrm{S}$ on 6 October is $6.9 \pm 0.9$ ppm $(1 \sigma)$. An analysis of the individual contributions of the different catalytic ozone depletion cycles was performed. Figure 8 shows the ozone depletion rates averaged over the polar region $\left(70^{\circ}-90^{\circ} \mathrm{S}\right)$ outside the polar vortex as a function of time. Different colors correspond to different ozone loss cycles. About 40\%$50 \%$ of the ozone depletion rate in the polar region is caused by the catalytic ozone depletion cycles involving $\mathrm{NO}_{x}$, about $20 \%$ is caused by $\mathrm{HO}_{x}$ cycles, and about $15 \%$ is caused by the reaction of $\mathrm{O}_{3}$ with $\mathrm{O}$. The black
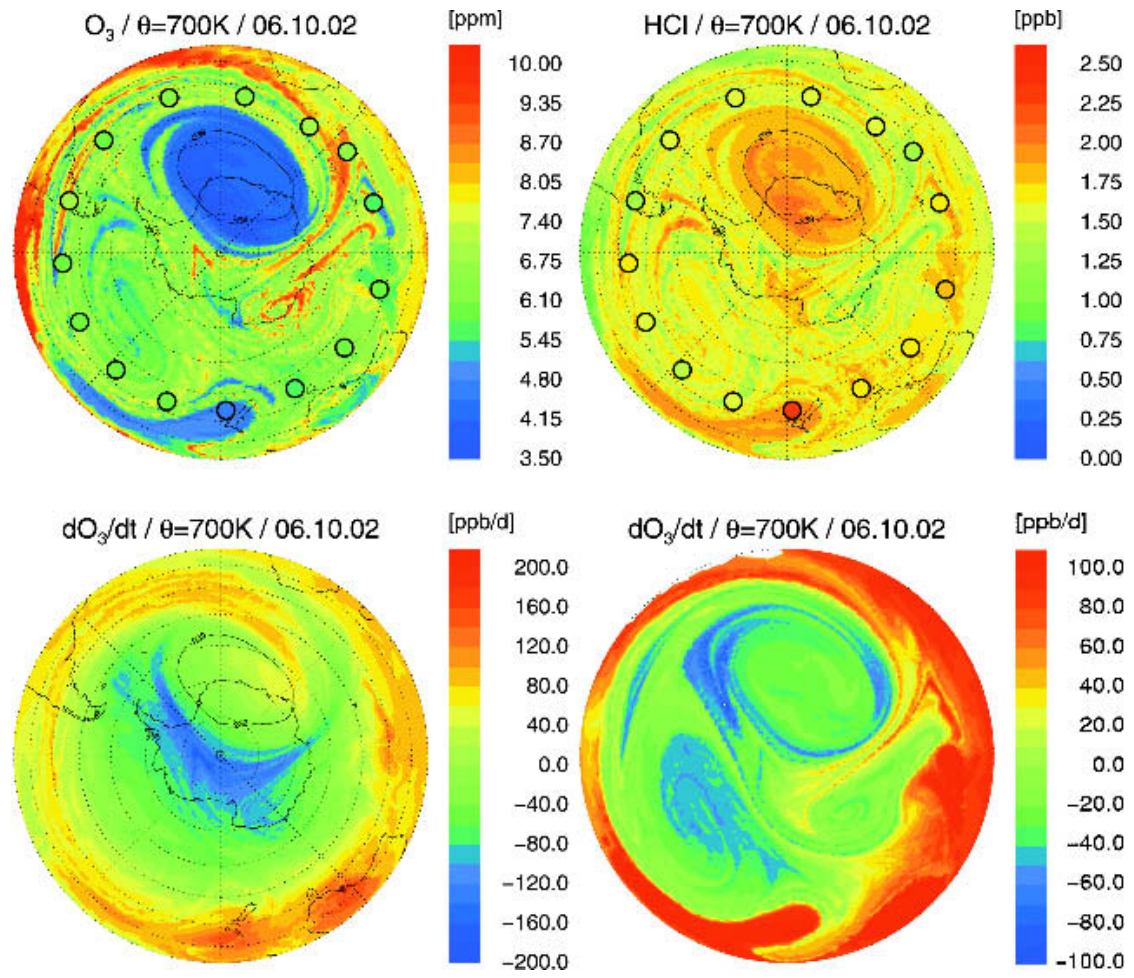

FIG. 7. Results of the CLaMS simulation of $\mathrm{O}_{3}, \mathrm{HCl}$, and ozone depletion rate at the 700-K level for 6 Oct 2002 at 1200 UTC. The colored circles show the locations and mixing ratios of the HALOE sunrise observations adjusted to 1200 UTC synoptic locations. (bottom left) The simulated ozone depletion rate averaged over 1 day and (bottom right) the simulated ozone depletion rate averaged over the last 7 days. 


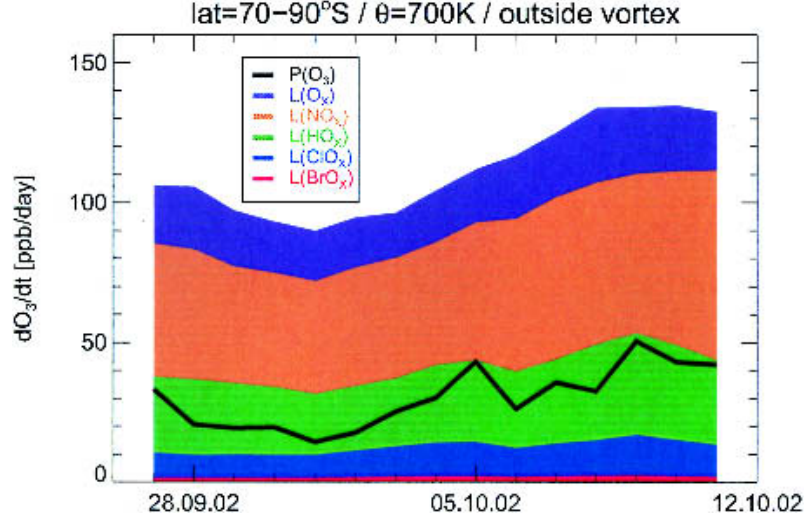

FIG. 8. Ozone production and depletion rates outside the vortex at the $700-\mathrm{K}$ potential temperature level. Shown are the individual contributions to different ozone loss cycles by different colors (see legend) averaged over outside vortex air masses poleward of $70^{\circ} \mathrm{S}$ for the time between $28 \mathrm{Sep}$ and 10 Oct.

line shows the ozone production rate. The total ozone depletion rate (without ozone production) averaged over this polar latitude region outside the vortex is about 70-100 ppb day ${ }^{-1}$. This effect is normally seen in the polar summer, especially if midlatitude air masses are transported to the polar region with continuous daylight (Farman 1985; Brühl et al. 1998). Loss of $\mathrm{NO}_{x}$ catalyzed ozone is the reason for the natural regular ozone depletion in polar summer and has been investigated in great detail in 1997 during the Photochemistry of Ozone Loss in the Arctic Region in Summer (POLARIS) campaign (e.g., Fahey and Ravishankara 1999; Newman et al. 1999). Because of the untypical meteorology during the 2002 major warming event, the conditions for this polar summer chemistry occurred much earlier, namely, just after the solstice when continuous daylight conditions over the pole began. The ozone depletion in midlatitude air masses that have been transported to the polar region was also derived from ENVISAT-MIPAS satellite data (Orsolini and Randall 2005).

\section{d. Sensitivity to denitrification}

With respect to chlorine deactivation, the denitrification, that is, the permanent removal of nitrogen compounds through sedimentation of $\mathrm{HNO}_{3}$-containing PSC particles, is also important. The formation of the reservoir $\mathrm{ClONO}_{2}$, caused by the reaction of $\mathrm{ClO}$ with $\mathrm{NO}_{2}$, depends on the availability of reactive nitrogen species. However, the formation of $\mathrm{HCl}$ does not proceed as explained above. To investigate the impact that denitrification may have on the simulation results, sensitivity simulations were performed in which the assumptions of the denitrification parameterization were varied. Denitrification is parameterized by introducing a $\mathrm{NO}_{y}$ loss rate proportional to the modeled PSC particle-settling velocity. With a proportionality factor given by the inverse of the so-called "characteristic height" of $250 \mathrm{~m}$, good agreement between observed and simulated $\mathrm{NO}_{y}$ was reached in the Arctic winter of 1999/2000 (Grooß et al. 2002). This parameter value was used in the reference simulation above (Ref). Two additional simulations were performed. In one simulation, the denitrification was completely switched off (NoDenit), while in the second simulation, the characteristic height was set to $125 \mathrm{~m}$, yielding a doubling of the denitrification rate (Denit2). For 24 September, the average vortex denitrification at the $475-$ and $550-\mathrm{K}$ levels in the reference simulation (Ref) is $42 \%$ and $44 \%$, respectively. In the simulation Denit2, the average vortex denitrification at the 475 - and $550-\mathrm{K}$ levels is $57 \%$ and $59 \%$, respectively. In the vortex core, the simulated denitrification is greater, namely, $52 \%$ and $49 \%$ in the reference simulation (Ref) and $68 \%$ and $64 \%$ in the simulation Denit2, respectively.

Figure 9 shows the simulated ozone depletion rates averaged over the polar vortex for these three denitrification parameterizations at the 475- and 550-K levels. The main effect of denitrification can be seen as a prolonged ozone depletion period. However, the simulated ozone depletion rates are very similar, and the prolongation of chemical ozone depletion is about 1 day between simulations NoDenit and Ref as well as between simulations Ref and Denit2. More denitrification causes higher ozone depletion. The vortex average ozone mixing ratios achieved using the mentioned denitrification parameterizations are summarized in Table 1. The results are shown for three dates: the initialization time (1 September), just before the vortex split (18 September), and after chlorine deactivation (30 September). By 30 September, the average ozone mixing ratio varied by about $\pm 4 \%$ of the initial ozone mixing ratio because of the different denitrification assumptions.

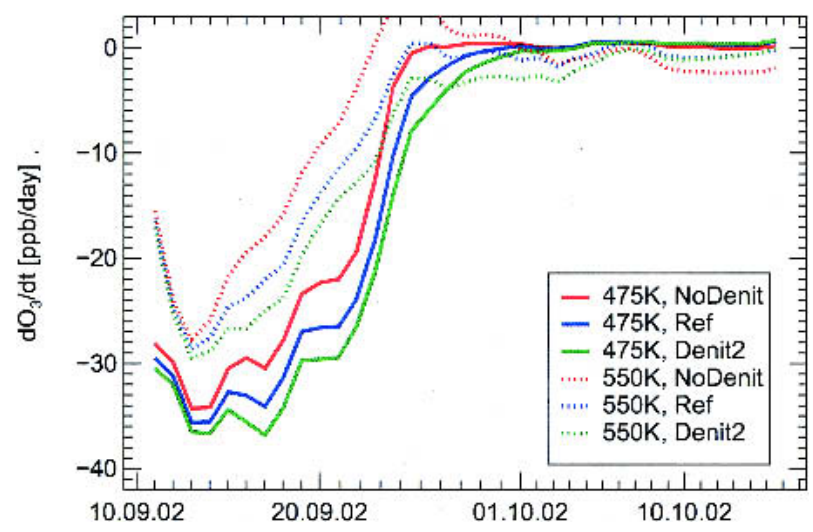

FIG. 9. Sensitivity to the denitrification parameterization Shown are the derived vortex-averaged ozone depletion rates at the 475- and 550-K levels for the three simulations: NoDenit, Ref, and Denit2. Solid lines show the results for the 475-K level, and dotted lines correspond to the 550-K level. 
TABLE 1. Sensitivity of simulated vortex average ozone mixing ratio in $\mathrm{ppm}$ with respect to denitrification parameterization. Shown are the three dates and two isentropic levels for the three simulations: NoDenit, Ref, and Denit2. The percent change with respect to the initialization date is displayed in parentheses. For details, see text.

\begin{tabular}{llll}
\hline \hline $\begin{array}{c}\text { Vortex } \\
\mathrm{O}_{3}(\mathrm{ppm})\end{array}$ & \multicolumn{1}{c}{ NoDenit } & \multicolumn{1}{c}{ Ref } & \multicolumn{1}{c}{ Denit2 } \\
\hline 1 Sep, 475 K & 1.35 & 1.35 & 1.35 \\
18 Sep, 475 K & $0.964(-28 \%)$ & $0.939(-30 \%)$ & $0.919(-32 \%)$ \\
30 Sep, 475 K & $0.796(-41 \%)$ & $0.726(-46 \%)$ & $0.670(-50 \%)$ \\
1 Sep, 550 K & 2.05 & 2.05 & 2.05 \\
18 Sep, 550 K & $1.59(-22 \%)$ & $1.56(-24 \%)$ & $1.53(-25 \%)$ \\
30 Sep, 550 K & $1.48(-28 \%)$ & $1.40(-32 \%)$ & $1.31(-36 \%)$ \\
\hline
\end{tabular}

\section{e. Influence of vortex fragments on midlatitude ozone}

Because of the major warming, a significant fraction of vortex air was transported into the midlatitudes. These air masses of vortex origin have a different chemical composition than the surrounding air caused by both diabatic descent and chemical ozone depletion within the polar vortex. The influence of vortex origin air that is transported to the midlatitudes has been investigated for typical Antarctic winters by Prather et al. (1990) and Prather and Jaffe (1990). They find that additional ozone depletion is unlikely to occur in these perturbed air masses and that the main effect is dilution of midlatitude ozone. In this section, we investigate the effect of the 2002 major warming on midlatitude ozone. To begin with, there is the pure dynamical effect, that is, transport of ozone-poor air into the midlatitudes and mixing with surrounding air resulting in the dilution of ozone. Furthermore, the influence of chemical ozone depletion caused by different chemical composition of the air masses is investigated. To perform this analysis, a vortex tracer was defined. Air masses that were located within the vortex on 18 September (before the vortex split) according to the criterion of Nash et al. (1996) were assigned a vortex tracer value of 1 , while elsewhere the vortex tracer was set to 0 . This vortex tracer was carried along the CLaMS air parcels and underwent transport and mixing in the same way as the chemical tracers. In this way, at a later time, air masses of vortex origin and the fraction of vortex air can be distinguished. Figure 10a shows the ozone mixing ratio at the 500-K level averaged between $30^{\circ}$ and $40^{\circ} \mathrm{S}$ latitude versus time (green line). The red line depicts the average over only those air masses that are not of vortex origin (vortex tracer $<0.05$ ), while the blue line shows the average ozone mixing ratio within the air masses of vortex origin (vortex tracer $>0.05$ ). Before 29 September, the vortex air masses did not reach the latitude belt under consideration. For the following 6 days, vortex air masses with relatively high ozone originating from the vortex edge (cf. Fig. 3a) reached the latitude belt under consideration. At 18 September, the average vortex ozone mixing ratio $( \pm 1 \sigma)$ was $1.2 \pm 0.7$

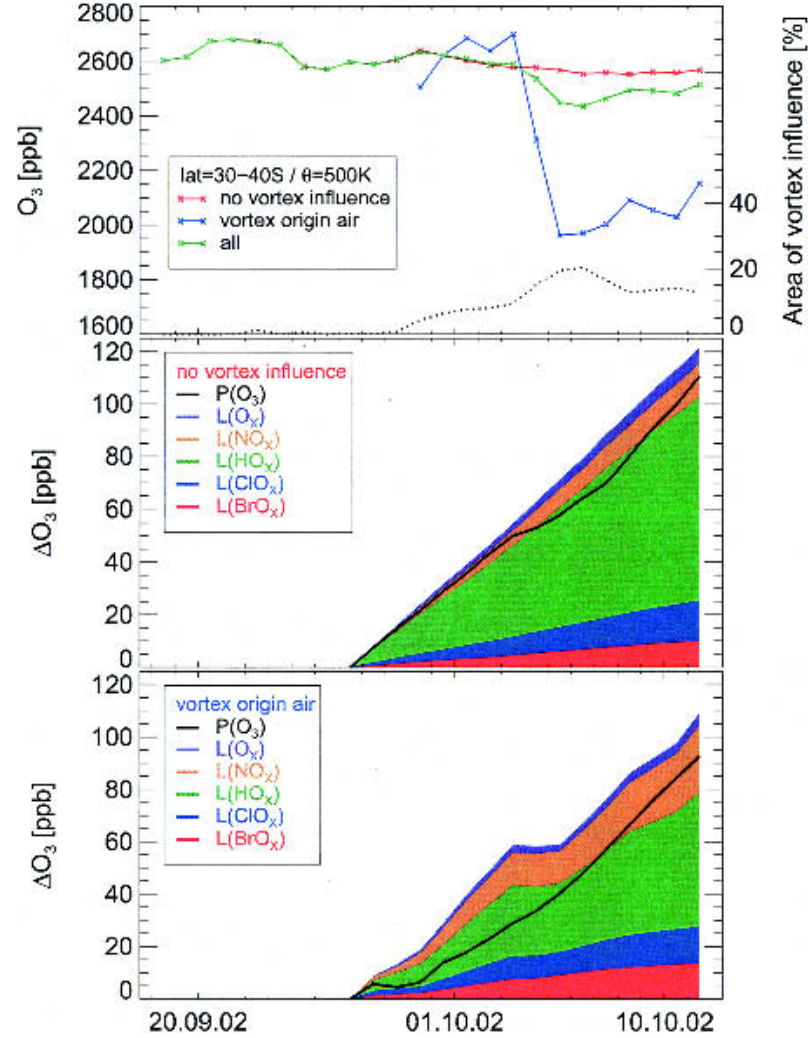

FIG. 10. Effect of vortex origin air on the midlatitudes between $30^{\circ}$ and $40^{\circ} \mathrm{S}$ at $\theta=500 \mathrm{~K}$. (top) The average ozone mixing ratio (green line) as well as the average of air masses without vortex contribution (red line) and the vortex air masses within this latitude region. The black dotted line shows the fraction of the latitude belt that is covered with air of vortex origin (right $y$ axis). (middle),(bottom) The integrated ozone production and ozone loss in the corresponding air masses divided into the different ozone loss cycles starting from 26 Sep, shortly after the vortex split.

ppm at $500 \mathrm{~K}$. From 5 October on, the air masses of vortex origin show a lower ozone mixing ratio by up to $600 \mathrm{ppb}$ compared with the undisturbed midlatitudes at the 500-K level. The black dotted line indicates the fraction of the latitude belt that is covered with air of vortex origin, which amounts to $20 \%$ at the $500-\mathrm{K}$ level. The difference between the red and green lines is the ozone change caused by the major warming, resulting in about $120 \mathrm{ppb}$ or $5 \%$ on 6 October on this level. On the higher levels, the influence of the vortex increased as larger fractions of the vortex were transported to the midlatitudes (Konopka et al. 2005). Between 550 and $700 \mathrm{~K}, 30 \%-43 \%$ of the zonal ring is of vortex origin, thus introducing a decrease in the average ozone mixing ratio of $12.5 \%-14.5 \%$ (not shown).

Besides this pure dynamical effect of transport and mixing, further investigations considered whether the different chemical composition of the vortex air masses yields differences in the ozone depletion rates. Thus, the chemical ozone depletion in the model was also 
traced in the air parcels divided into the individual catalytic cycles involved in the ozone depletion starting on 26 September, shortly after the vortex split. By that time, the chlorine compounds in the vortex were already deactivated into the reservoirs $\mathrm{ClONO}_{2}$ and $\mathrm{HCl}$, as explained above. Thus, chlorine and bromine chemistry do not play a major role in these vortex filaments. Figures $10 \mathrm{~b}$ and $\mathrm{c}$ indicate the integrated ozone loss since that date in the $30^{\circ}-40^{\circ} \mathrm{S}$ latitude belt for air without vortex influence and vortex air, respectively. The integrated loss attributed to the different loss cycles is indicated by different colors. The integrated ozone production is depicted as a black line. From that, it can be seen that in the vortex air masses $\mathrm{NO}_{\mathrm{x}}$-catalyzed loss does play a larger role caused by the previous diabetic descent of $\mathrm{NO}_{\mathrm{y}}$-rich air in the vortex (even though some of the $\mathrm{NO}_{\mathrm{y}}$ is removed by denitrification). For both air masses with and without vortex origin, the integrated ozone loss slightly exceeds the ozone production. However, the amount of net ozone loss (ozone loss minus ozone production) is small and very similar for both types of air masses (11 and 16 ppb on 11 October). The difference in chemical ozone loss is much smaller than the absolute difference of the ozone mixing ratio (up to $600 \mathrm{ppb}$ ) for both types of air masses. Therefore, the chemical ozone loss is negligible compared with the dynamical effect, a finding that is in agreement with the results for typical Antarctic winters (Prather and Jaffe 1990).

\section{Conclusions}

The CLaMS simulations presented show the specific features of stratospheric chemistry caused by the split of the polar vortex in September 2002. In spite of some simplifications made in a few underlying model assumptions (initialization, denitrification, and isentropic approximation), the simulation shows good agreement with HALOE observations. In particular, the location and the observed mixing ratios for the air masses in the midlatitudes that originated from the polar vortex are well reproduced. The simulation indicates rapid chlorine deactivation after the major warming as soon as PSCs disappear. The deactivation yields the two different reservoirs, $\mathrm{HCl}$ and $\mathrm{ClONO}_{2}$, depending on the value of the ozone mixing ratio. Note that the spatial distribution of ozone mixing ratios inside the vortex is rather inhomogeneous. Very low ozone mixing ratios favor the formation of $\mathrm{HCl}$, while in the case of higher ozone mixing ratios and less denitrification, $\mathrm{ClONO}_{2}$ is formed. In the polar vortex air masses, the ozone depletion rates decrease rapidly, corresponding to the rapid chlorine deactivation. At greater altitudes (about $700 \mathrm{~K}$ ), the complete polar vortex is shifted off the pole. The air masses that were in turn transported from the midlatitudes to the polar region experience very high ozone depletion rates mostly caused by $\mathrm{NO}_{x}$ catalytic cycles that are typical of polar summer chemistry. The ozone depletion rate over the polar region south of $70^{\circ} \mathrm{S}$ outside the vortex was about $70-100 \mathrm{ppb} \mathrm{day}^{-1}$ on this level. The fraction of the ozone-poor vortex air that is transported and mixed into the midlatitudes after the vortex split dilutes the ozone in the midlatitudes, causing a decrease of zonal-mean ozone by up to $5 \%$ on the $475-500-\mathrm{K}$ levels and by about $15 \%$ on the $550-700-\mathrm{K}$ levels. In these air masses, the effect of in situ chemical ozone depletion can be neglected compared to this dynamical effect.

Acknowledgments. The authors thank the HALOE team, especially James M. Russell III, Earl Thompson, and Lance Deaver, for continuous support. The European Centre for Medium-Range Weather Forecasts (ECMWF) kindly provided the meteorological analysis data. We also thank the two anonymous reviewers for their constructive comments. This work was supported by the German HGF-Vernetzungsfonds.

\section{REFERENCES}

Brühl, C., P. J. Crutzen, and J.-U. Grooß, 1998: High-latitude, summertime NOx activation and seasonal ozone decline in the lower stratosphere: Model calculations based on observations by HALOE on UARS. J. Geophys. Res., 103 (D3), 3587-3597.

Douglass, A. R., M. R. Schoeberl, R. S. Stolarski, J. W. Waters, J. M. Russell III, A. E. Roche, and S. T. Massie, 1995: Interhemispheric differences in springtime production of $\mathrm{HCl}$ and $\mathrm{ClONO}_{2}$ in the polar vortices. J. Geophys. Res., 100, $13967-$ 13978.

Fahey, D., and A. Ravishankara, 1999: Summer in the stratosphere. Science, 285, 208-210.

Farman, J. C., 1985: Ozone photochemistry in the Antarctic stratosphere in summer. Quart. J. Roy. Meteor. Soc., 111, 1013-1025.

Grooß, J.-U., 1996: Modelling of stratospheric chemistry based on HALOE/UARS satellite data. Ph.D. thesis, University of Mainz, $135 \mathrm{pp}$.

- R. B. Pierce, P. J. Crutzen, W. L. Grose, and J. M. Russell III, 1997: Reformation of chlorine reservoirs in Southern Hemisphere polar spring. J. Geophys. Res., 102, 13 141-13 152.

- and Coauthors, 2002: Simulation of ozone depletion in spring 2000 with the Chemical Lagrangian Model of the Stratosphere (CLaMS). J. Geophys. Res., 107, 8295, doi:10.1029/2001JD000456.

Hoppel, K., R. Bevilacqua, D. Allen, G. Nedoluha, and C. Randall, 2003: POAM III observations of the anomalous 2002 Antarctic ozone hole. Geophys. Res. Lett., 30, 1394, doi:10.1029/2003GL016899.

Konopka, P., J.-U. Grooß, S. Bausch, R. Müller, D. S. McKenna, O. Morgenstern, and Y. Orsolini, 2003a: Dynamics and chemistry of vortex remnants in late Arctic spring 1997 and 2000: Simulations with the Chemical Lagrangian Model of the Stratosphere (CLaMS). Atmos. Chem. Phys., 3, 839-849.

,- G. Günther, D. S. McKenna, R. Müller, J. W. Elkins, D. Fahey, and P. Popp, 2003b: Weak impact of mixing on chlorine deactivation during SOLVE/THESEO2000: Lagrangian modeling (CLaMS) versus ER-2 in situ observations. J. Geophys. Res., 108, 8324, doi:10.1029/2001JD000876.

,-- H.-M. Steinhorst, and R. Müller, 2005: Mixing and chemical ozone loss during and after the Antarctic polar vortex major warming in September 2002. J. Atmos. Sci., 62, 848-859.

McKenna, D. S., J.-U. Grooß, G. Günther, P. Konopka, R. Müller, G. Carver, and Y. Sasano, 2002a: A new Chemical 
Lagrangian Model of the Stratosphere (CLaMS) 2. Formulation of chemistry scheme and initialization. J. Geophys. Res., 107, 4256, doi:10.1029/2000JD000113.

— , P. Konopka, J.-U. Grooß, G. Günther, R. Müller, R. Spang, D. Offermann, and Y. Orsolini, 2002b: A new Chemical Lagrangian Model of the Stratosphere (CLaMS) 1. Formulation of advection and mixing. J. Geophys. Res., 107, 4309, doi:10.1029/2000JD000114.

Morcrette, J.-J., 1991: Radiation and cloud radiative properties in the European Centre for Medium-Range Weather Forecasts forecasting system. J. Geophys. Res., 96 (D5), 9121-9132.

Nash, E. R., P. A. Newman, J. E. Rosenfield, and M. R. Schoeberl, 1996: An objective determination of the polar vortex using Ertel's potential vorticity. J. Geophys. Res., 101, 9471-9478.

Newman, P., and E. Nash, 2005: The unusual Southern Hemisphere stratosphere winter of 2002. J. Atmos. Sci., 62, 614628.

, D. W. Fahey, W. B. Brune, and M. J. Kurylo, 1999: Preface to POLARIS special section. J. Geophys. Res., 104 (D21), 26 481-26 495
Orsolini, Y. J., and C. Randall, 2005: An observational study of the final breakdown of the Southern Hemisphere stratospheric vortex in 2002. J. Atmos. Sci., 62, 735-747.

Prather, M., and A. H. Jaffe, 1990: Global impact of the Antarctic ozone hole: Chemical propagation. J. Geophys. Res., 95, 3473-3492.

- M. M. Garcia, R. Suozzo, and D. Rind, 1990: Global impact of the Antarctic ozone hole: Dynamical dilution with a threedimensional Chemical Transport Model. J. Geophys. Res., 95, 3449-3471.

Russell, J. M., and Coauthors, 1993: The Halogen Occultation Experiment. J. Geophys. Res., 98, 10 777-10 797.

Sinnhuber, B.-M., M. Weber, A. Amankwah, and J. P. Burrows, 2003: Total ozone during the unusual Antarctic winter of 2002. Geophys. Res. Lett., 30, 1580, doi:10.1029/ 2002GL016798.

Toon, G. C., C. B. Farmer, L. L. Lowes, P. W. Schaper, J. F. Blavier, and R. H. Norton, 1989: Infrared aircraft measurements of stratospheric composition over Antarctica during September 1987. J. Geophys. Res., 94 (D14), 16 571-16 596. 